\title{
The effect of roll back malaria programme on farmers productivity in Benue State, Nigeria
}

\author{
Obekpa H. O.*, Abu G. A. and Aye G. C. \\ Department of Agricultural Economics, College of Agricultural Economics and Extension, University of Agriculture, \\ Makurdi, Benue State, Nigeria.
}

Received 25 June, 2015; Accepted 9 September, 2015

\begin{abstract}
The study analyzed the effect of Roll Back Malaria Programme (RBM) on farmer's productivity in Benue State of Nigeria. Roll Back Malaria Programme is a global framework for coordinated action against malaria. A multi-stage random sampling technique was used in selecting 206 respondents from six Local Governments Areas. Data was collected with the aid of well structured questionnaires. The CobbDouglas stochastic production frontier was used for data analysis. The study showed that farm size, hired labour and quantity of seeds had positive and significant influence on farmer's output in a production pattern that exhibited decreasing return to scale (0.95). The study found technical efficiency of the farmers to vary from 0.14 to 0.95 with a mean of 0.71 . Furthermore, farmer's experience $(-2.68)$, use of LLIN (-2.42), access to healthcare $(-1.84)$ and sex of farmer $(-2.12)$ were found to reduce farmer's technical inefficiency. However, increase in sanitation (1.77) increased farmers' technical inefficiency in the study area. The study recommends that productivity of factors could be improved by expanding the farm size at the existing level of hired labour. Also, enlightenment programmes on the benefits of RBM and enlightenment campaigns should be encouraged for better and efficient production.
\end{abstract}

Key words: Effect, malaria, programme, farmers, productivity, Nigeria.

\section{INTRODUCTION}

Malaria is a health problem caused by plasmodium parasites. Malaria attacks an individual an average of four times in a year with an average of 10 to 14 days of incapacitation (Alaba and Alaba, 2002). The frequency of malaria illness and criticality of associated morbidity often portend the disease as a serious economic problem. In many African communities, malaria is a household name with strong resilience and adaptability to different combinations of drugs. In addition to its health impact, malaria is an obstacle to economic development. The goal of the RBM is to halve the malaria burden through interventions that are adapted to local needs. The evolution of new tools (e.g. new Long-Lasting Insecticidetreated mosquito Nets [LLINs], Rapid Diagnostic Tests [RDTs], new drugs) and new strategies (scale-up for impact, expanding from a targeted approach to reach all at-risk people, seeking elimination where possible) is indicative of a partnership that has quickly matured and become responsive to diverse and rapidly changing needs and situations (Lagos State Ministry of Health, 2014). Malaria and agriculture are related. This implies that there may be a bi-directional relationship between

${ }^{*}$ Corresponding author. E-mail: atamahephzibah@yahoo.com Author(s) agree that this article remain permanently open access under the terms of the Creative Commons Attribution License 4.0 International License 
agriculture and malaria.

On one hand, agricultural environment provides suitable conditions for breeding of disease vectors which cause malaria in human beings. On the other hand malaria is capable of fuelling the nation's poverty situation by inhibiting critical investment plans in agriculture at the households level. Some socio-cultural practices of farmers also indirectly aid breeding of mosquito vectors. Every year the nation loses about $\mathrm{N} 132$ billion to malaria in man hours, while the illness drops the nation's annual Gross Domestic Product by $1 \%$ (Ogundipe, 2013).

Malaria is still a big healthcare issue in Nigeria and the effect trickles down to agriculture. Rural and semimodern Nigeria is largely agrarian, thus, the effects of malaria on agriculture, health and development are widespread (Babalola et al., 2009). There are multiple channels by which malaria impedes development, including effects on fertility, population growth, savings and investment, worker productivity, absenteeism, premature mortality and medical costs (Sachs and Malaney, 2010).

The Roll Back Malaria Programme faces challenges with farmer's socio-economic and socio-cultural behaviours in respect to adoption of the LLIN. Against the background of a deteriorating malaria situation and severe economic hardships particularly in Nigeria, this study is important.

Currently, studies on RBM are limited especially in the Benue state context. The only known study is that of Ogbegbor (2014), who evaluated the managerial and the socioeconomic issues in the realization of RBM in Benue State. In respect of this research gap, this study aims at investigating the effect of RBM on farm household's productivity in Benue state.

\section{MATERIALS AND METHODS}

\section{The study area}

The study was conducted in Benue state, Nigeria. The State lies between longitude $7^{\circ} 47^{\prime} \mathrm{E}$ and $10^{\circ} \mathrm{E}$ and latitude $6^{\circ} 25^{\prime} \mathrm{N}$ and $8^{\circ} 8^{\prime} \mathrm{N}$ of the equator (NPC, 2013). Benue state experiences a mean rainfall of $1500 \mathrm{~mm}$ and a temperature ranging from $24^{\circ} \mathrm{C}$ to $36^{\circ} \mathrm{C}$ and is at an elevation of $97 \mathrm{~m}$ above sea level in the southern guinea savannah agro ecological zone. The major occupation of people in the state is farming, these qualities make the study area suitable for malaria and productivity related research.

\section{Sampling technique and sample size}

The population for this study consisted of all farmer households in Benue State. The respondents were selected using multi-stage random sampling technique. The first stage involved the selection of two local governments from each of the three senatorial zones using simple random sampling technique; the second stage involved random selection of one council ward from each selected local government. The final stage involved a simple random selection of $5 \%$ of the total households in each council ward. Thus, a total of 206 respondents were selected including both beneficiaries and non-beneficiaries of the Roll Back Malaria Programme.

\section{Method of data analysis}

The stochastic production frontier model was used to analyze the productivity of farmers.

\section{Empirical specification}

The Stochastic production function used to analyze the productivity of farmers and was specified by the Cobb-Douglas frontier production function and it represented as follows:

$\ln Q=\beta_{0}+\beta_{1} \ln X_{1 i}+\beta_{2} \ln X_{2 i}+\beta_{3 i} \ln X_{3 i}+\beta_{4 i} \ln X_{4 i}+\beta_{5 i} \ln X_{5 i}+$

$V_{i}-U_{i}$

Where $Q$ is total value of output of the farmer in naira; $\beta$ s are the parameters to be estimated; $X_{1}$ is farm size in hectares; $X_{2}$ is quantity of seeds in $\mathrm{kg}$; $X_{3}$ us fertilizers applied per hectare in $\mathrm{kg} / \mathrm{ha}$; $\mathrm{X}_{4}$ is family labour in man-days; $\mathrm{X}_{5}$ is hired labour in Naira; $V_{i}$ is Random error that is assumed to be normally distributed with zero mean and constant variance; $U_{i}=$ non negative random variable associated with technical inefficiency of production. The inefficiency of production is modelled in terms of factors that are assumed to be independently distributed such that $U_{i}$ is obtained by truncation (at zero) of the normal distribution with variance $\delta^{2}$ and mean $u$ where the mean is defined by:

$U_{i}=\sigma_{0}+\sigma_{1} z_{1 i}+\sigma_{2} z_{2 i}+\sigma_{3} z_{3 i}+\sigma_{4} z_{4 i}+\sigma_{5} z_{5 i}+\sigma_{6} z_{6 i}+\sigma_{7} z_{7 i}$

Where; $Z_{1}=$ Age of respondents (years); $Z_{2}=$ Educational attainment (years); $Z_{3}=$ Household size; $Z_{4}=$ Years of experience in farming (years); $Z=$ Use of LLIN (Use=1, Otherwise $=0$ ); $Z_{6}=$ Sanitation (Clean environment $=1$, Otherwise $=0$ ); $Z_{7}=$ Access to RBM health care (Very far $=4, F a r=3$, Close $=2$, Very close $=1) ; Z_{8}=$ Sex (Male=1, Female $=0)$.

These variables are assumed to influence technical inefficiency of the farmers. The gamma $\left(\gamma=\sigma^{2}{ }_{u} /\left(\sigma^{2}{ }_{u}+\sigma^{2} v\right)\right.$ which is the ratio of the variance of $u\left(\sigma^{2} u\right)$ to the Sigma squared $\left(\sigma^{2}\right)$ which is the summation of variance of $U$ and $V\left(\sigma^{2}=\sigma^{2} u+\sigma^{2} v\right)$ were also determined. Maximum likelihood estimates of parameters of the stochastic frontier and the inefficiency models were simultaneously estimated using Frontier 4.1 developed by Battese and Coelli (1995).

The technical efficiency of an individual firm is defined in terms of the observed output $\left(Q_{i}\right)$ to the corresponding frontier output $\left(Q_{i}^{*}\right)$ given the available technology. This could be expressed mathematically as:

$T . E=Q_{i} / Q_{i}^{*}$

Where: $Q_{i}=$ Observed output; $Q_{i}^{*}=$ Frontier output

Equation 3 can also be expressed as:

T. E. $=Q_{i} / Q_{i}^{*}=\operatorname{Exp}\left(X_{i} \beta+V_{i}-U_{i}\right) / \operatorname{Exp}\left(X \beta+V_{i}\right)$

Where, $0 \leq \mathrm{TE} \leq 1$.

The presence of technical inefficiency effects was tested using the generalized likelihood ratio test $(\lambda)$, which is defined by:

$\lambda=-2\left(L_{R}-L_{U}\right)$

Where, $L_{R}=\log$ likelihood of the restricted model (model 1), and $L_{U}$ $=$ Log likelihood of the unrestricted model (model 2).

It is assumed that $\lambda$ has a mixed chi-square distribution with degree of freedom equal to the number of parameters excluded in 
Table 1. Maximum likelihood estimates of the stochastic production frontier function of the independent variables.

\begin{tabular}{lcc}
\hline Variables & Model 1 estimates & +Model 2 estimates \\
\hline Constant & $10.72\left(31.06^{\star}\right)$ & $11.78\left(33.59^{*}\right)$ \\
Farm size & $0.67\left(7.90^{*}\right)$ & $0.85\left(10.05^{\star}\right)$ \\
Quantity of seeds & $0.07(1.33)$ & $0.10\left(2.46^{\star \star}\right)$ \\
Quantity of fertilizer & $0.02(0.68)$ & $-0.02(-0.74)$ \\
Family labour & $0.04(0.99)$ & $-0.02(-0.55)$ \\
Hired labour & $0.07\left(7.65^{\star}\right)$ & $0.04\left(4.22^{*}\right)$ \\
Household size & - & $0.05(1.48)$ \\
Sigma squared $\left(\sigma^{2}\right)$ & 0.44 & $0.37\left(5.18^{*}\right)$ \\
Gamma & - & $0.39\left(2.62^{\star}\right)$ \\
Log likelihood function & -205.5 & 162.9 \\
Likelihood ratio $(\lambda)$ tabulated & & 15.51 \\
\hline
\end{tabular}

Source: Field Survey $2015 .+$, Lead model values in parenthesis represents t-ratio. ${ }^{*},{ }^{* *},{ }^{* * *}=\mathrm{t}$-ratio significant at 1,5 and $10 \%$ levels respectively.

the unrestricted model. The null hypothesis was that model 1 is equal to model 2 (the variance of the inefficiency effects, gamma $(\mathrm{Y})$ $=0$ ). The variables for the research and their measurement are as follows:

1. Age: The number of years of the household head. It was measured in years

2. Sex: The two main categories into which humans are divided on the basis of their reproductive function. It was measured as a dummy, male $=1$, female $=0$.

3. Income Level: The total amount of money earned by a household. It was measured in naira.

4. Education: This was measured as the number of years spent in acquiring formal education.

5. Household size: This was measured as the number of persons living in the same house, who share the same income with one household head.

6. Marital status: this was measured as married $=1$, otherwise $=0$.

7. Farm size: was measured in hectares.

8. Productivity: a measure of the efficiency of a household.

9. Malaria incidence: The number of cases of malaria a household has in a year.

10. Sanitation: The process of keeping places free from dirt, infection, disease etc by removing waste, trash and garbage. This was measured as Clean environment $=1$, Otherwise $=0$.

11. Access to health care: having the timely use of health services to achieve the best health outcomes. This was measured as Very far $=4$, Far $=3$, Close $=2$, Very close $=1$.

\section{RESULTS AND DISCUSSION}

\section{Estimates of the parameters of the stochastic production frontier function}

The maximum likelihood estimates (MLE) of the Cobb Douglas stochastic production frontier model and the ordinary least square (OLS) estimates are presented in Table 1. The results revealed the presence of inefficiency among farmers in the study area based on the significance of gamma and the likelihood ratio $(\lambda)$ test. The $\lambda$ test which has mixed chi-square $\left(x^{2}\right)$ distribution stood at 85.06 , while the critical value of chi-square at $95 \%$ confidence interval and 8 degree of freedom, $x^{2}{ }_{(0.05,8)}=$ 15.51, Thus the null hypothesis of no inefficiency effects $(y=0)$ was rejected (Model $1 \neq$ Model 2$)$. This means that the traditional frontier model estimated with ordinary least square (which is estimated without the inefficiency effects) is not the adequate representation of the data, hence Cobb-Douglas Stochastic production frontier model which described the farm's specific inefficiency effects fits this data better.

The value of sigma squared is 0.37 and it was statistically significant at $1 \%$ level of probability indicating a good fit and correctness of the distribution. It also implies that the Cobb Douglas stochastic production frontier is the adequate representation of the data. The variance of the ratio (Gamma) which measures the effect of technical efficiency in the variation of observed output is 0.39 and its significant at $1 \%$ indicating that $39 \%$ of reduction from the maximum output is as a result of inefficiency in management on the part of the farmer which could be overcome by adopting the Roll Back Malaria measures of preventing malaria infection and increasing the productivity of family labour as a result of good health.

The sum of elasticities of the coefficients which is a measure of return to scale of the farmers was less than unity (0.95) indicating a diminishing return to scale. This implies that an increase in the quantity of all inputs employed by farmers in production in the study area will result in less than proportionate increase in the quantity of output produced.

Thus, farmers in the study area can expand their production through additional use of inputs. This is in agreement with the works of Tsue et al. (2013) and Shehu 
Table 2. Maximum likelihood estimates of the stochastic production frontier function of the inefficiency model

\begin{tabular}{lcc}
\hline Hired labour & $\mathbf{0 . 0 7}\left(\mathbf{7 . 6 5 ^ { \star } )}\right.$ & $\mathbf{0 . 0 4}(\mathbf{4 . 2 2})$ \\
\hline Constant & - & $1.32\left(2.94^{\star}\right)$ \\
Age & - & $0.009(0.74)$ \\
Education & - & $-0.002(-0.10)$ \\
Household size & - & $0.05(1.48)$ \\
Experience & - & $-0.04\left(-2.68^{\star}\right)$ \\
Use of LLIN & - & $-0.006\left(-2.42^{\star \star}\right)$ \\
Sanitation & - & $0.32\left(1.77^{\star \star \star}\right)$ \\
Access to healthcare & - & $-0.02\left(-1.84^{\star \star \star}\right)$ \\
Sex & - & $-0.37\left(-2.12^{\star \star}\right)$ \\
Sigma squared $\left(\sigma^{2}\right)$ & 0.44 & $0.37\left(5.18^{\star}\right)$ \\
Gamma $(Y)$ & - & $0.39\left(2.62^{\star}\right)$ \\
Log Likelihood function & -205.5 & 162.9 \\
Likelihood ratio $(\lambda)$ calculated & & 85.06 \\
Likelihood ratio $(\lambda)$ tabulated & & 15.51 \\
\hline
\end{tabular}

Source: Field Survey, 2015.+ lead model Values in Parenthesis represents t-ratio. ${ }^{*},{ }^{* *},{ }^{* * *}=$ t-ratio significant at 1,5 and $10 \%$ levels, respectively.

et al. (2010) that found the return to scale of cat fish and yam farmers in Benue state to be 0.95 and 0.98 respectively, indicating that the farmers had diminishing returns to scale. The estimated elasticities of the independent variables revealed that farm size and hired labour were statistically significant at $1 \%$ level while quantity of seeds used was significant at $5 \%$ level.

More specifically, the result showed that farm size and hired labour were the most important factors for increasing the quantity of output of farmers in the study area as every $10 \%$ increment in the farm size and hired labour used increases the output of farmers by 8.5 and $0.4 \%$ respectively. This is however expected as large farm size with correspondent labour will increase the productivity of farmers.

\section{Technical inefficiency analysis}

Analysis of technical inefficiency model is Table 2 . Factors that were found to exert statistical influence on inefficiency of farmers include farming experience (-0.04), use of LLIN $(-0.006)$, Sanitation as a result of enlightenment (0.32), Access to health care $(-0.02)$ and sex of farmers $(-0.37)$.

However, age, educational attainment and household size were found not to exert statistical significance on the level of farmers' inefficiency. Specifically, the result showed that the more years of experience in farming a farmer has the lesser his technical inefficiency. This is because the more experience a farmer has, the more he is likely to become technically efficient, this result is supported by Wollini and Brummer (2012), that concluded that the most important factor that affects the level of technical efficiency of coffee farmers in Costa Rica was an experience in coffee production. Similarly, the more a farmer and his household make use of the long lasting insecticide treated nets (LLIN) the less likely they will get infected with malaria that is capable of keeping them away from farming activities either directly or indirectly and thus making them more technically efficient on the farm. Also, the positive and significant coefficient of sanitation on technical inefficiency model implies that this factor decreases technical efficiency of farmers in the study area. The negative relation between this variable and technical efficiency may be the case of farmers who think sanitation is enough measure to prevent malaria infection and increasing productivity.

Furthermore, access to health care increased farmer's technical efficiency, this is because when farmers fall sick because of mosquito bites and get rapid access to health care this helps to reduce the number of days they would have been incapacitated with malaria as a result of treatment they would have got from the health centres.

Alternatively, this implies that the more access to health care farmers get, the lesser their level of technical inefficiency. This is expected because when farmers are down with malaria and they get quick and prompt treatment from health care centres, they are more likely to recover on time thereby reducing the number of days they would have been incapacitated by malaria. The result also shows that having more males involved in farming activities, reduces technical inefficiency. This may be as a result of men giving more details to farming instruction than their female counterparts coupled with their ability to withstand the rigorous demands of farming 
Table 3. Frequency distribution of the technical efficiency estimates of the farmers.

\begin{tabular}{lcc}
\hline Range & Frequency & Percentage \\
\hline$\leq 0.30$ & 15 & 7.3 \\
$0.31-0.60$ & 48 & 23.3 \\
$0.61-0.90$ & 74 & 35.9 \\
$\geq 0.91$ & 69 & 33.5 \\
Mean & 0.71 & \\
Minimum & 0.14 & \\
Maximum & 0.95 & \\
\hline
\end{tabular}

Source: Field survey, 2015.

compared to the female folks.

\section{Efficiency estimates of farmers in Benue State}

The frequency distribution of the estimated technical efficiency is presented in Table 3 . The result revealed that technical efficiency of farmers ranged between 0.14 and 0.95 with a mean of 0.71 which is less than unity indicating that the farmers are producing below the maximum technical efficiency frontier. This implies that technical efficiency of farmers in Benue could be increased by $29 \%$ through efficient use of available resources given the current state of technology. The results further showed that about $69.4 \%$ of the farmers had technical efficiency exceeding $60 \%$.

\section{CONCLUSION AND RECOMMENDATION}

The study revealed that farm size, quantity of seeds and hired labour had significant effect on the output of farmers. The study further found out that technical efficiency of farmers varied due to the presence of inefficiency effects on the part of management. Specifically, years of schooling, farming experience, use of LLIN, access to health care and male farmers increased the technical efficiency of farmers while increase in sanitation decreased their technical efficiency.

The result indicates that RBM has helped improved the productivity of the farmers even though the return to scale was 0.95 (diminishing returns). The mean technical efficiency of the farmers is 71 percent. This suggests that the technical efficiency could be increased by $29 \%$ if the available resources are efficiently utilized. The study recommends that productivity of factors could be improved by expanding the farm size at the existing level of hired labour. Also, enlightenment programmes on the benefits of RBM and enlightenment campaigns should be encouraged for better and efficient production.

\section{Conflict of Interest}

The authors have not declared any conflict of interest.

\section{REFERENCES}

Alaba OA, Alaba OB (2002). Malaria in children implication for the productivity of female caregivers in Nigeria. Proceeding of annual conference of the Nigerian Economic Society (NES), pp. 395-413.

Babalola DA, Awoyemi TT, Awoyinka,YA (2009). Effects of Malaria on Rural Farming household Labour supply: the case of Ikenne Local Government, Ogun state, Nigeria. J. Life Phys. Sci. 3(1):19-24.

Battese GE, Coelli TJ (1995). A Model for Technical Inefficiency Effects in a Stochastic Frontier Production function for Panel Data. Emp. Econ. 20:325-332

Lagos State Ministry of Health (2014). Retrieved on the $20^{\text {th }}$ of October, $2014 . \quad$ http:www.Ismoh.com/programmes/malaria-controlprogram\#.VZZXjLGYgVA

National Population Commission census (2013). National Population commission Estimate.

Ogbegbor G (2014). An Evaluation of the Managerial and Socioeconomic Issues in the Realization of Roll Back Malaria in Benue State. Unpublished Thesis.

Ogundipe S (2013). Affordable Malaria Treatment Still a Bitter Pill to Swallow. Retrieved on $10^{\text {th }}$ September, 2014, from http://www.vanguardngr.com/2013/07/affordable-malaria-treatmentstill-a-bitter-pill-to-swallow.

Sachs J, Malaney P (2010). The economic and social burden $f$ Malaria. Insight Review Articles. Center for International Development, John F. Kennedy School of Government, Harvard University.

Shehu JF, lyortyer JT, Mshelia SI, Jongur AAU (2010). Determinants of Yam Production and Technical Efficiency among Yam Farmers in Benue State, Nigeira. J. Soc. Sci. 24(2):143-148.

Tsue PT, Lawal WL, Ayuba VO (2013). Productivity and Technical Efficiency of Catfish Farmers in Benue state, Nigeria. Adv. J. Agric. Res. 1(2):20-25.

Wollini M, Brummer B (2012). Productive Efficiency of Specialty and Coventional Coffe Farmers in Costa Rica: Accounting for Technological Heterogeneity and Self Selection. Food Policy 37:6776. 